\title{
Brine-Induced Tribocorrosion Accelerates Wear on Stainless Steel: Implications for Mars Exploration
}

\author{
Javier Martín-Torres $\mathbb{D D}^{1,2}$ María-Paz Zorzano-Mier, ${ }^{1,3}$ Erik Nyberg $\mathbb{D}^{4}{ }^{4}$ \\ Abhilash Vakkada-Ramachandran $\mathbb{D}^{\mathbb{D}},{ }^{4}$ and Anshuman Bhardwaj $\mathbb{D}^{1}$ \\ ${ }^{1}$ Department of Planetary Sciences, School of Geosciences, University of Aberdeen, King's College, Aberdeen AB24 $3 U E$, UK \\ ${ }^{2}$ Instituto Andaluz de Ciencias de La Tierra (CSIC-UGR), Granada, Spain \\ ${ }^{3}$ Centro de Astrobiología (INTA-CSIC), Madrid, Spain \\ ${ }^{4}$ Department of Computer Science, Electrical and Space Engineering, Luleå University of Technology, Luleå, Sweden
}

Correspondence should be addressed to Javier Martín-Torres; javier.martin-torres@abdn.ac.uk

Received 1 June 2021; Revised 22 November 2021; Accepted 13 December 2021; Published 28 December 2021

Academic Editor: Yu Liu

Copyright ( $\odot 2021$ Javier Martín-Torres et al. This is an open access article distributed under the Creative Commons Attribution License, which permits unrestricted use, distribution, and reproduction in any medium, provided the original work is properly cited.

\begin{abstract}
Tribocorrosion is a degradation phenomenon of material surfaces subjected to the combined action of mechanical loading and corrosion attack caused by the environment. Although corrosive chemical species such as materials like chloride atoms, chlorides, and perchlorates have been detected on the Martian surface, there is a lack of studies of its impact on materials for landed spacecraft and structures that will support surface operations on Mars. Here, we present a series of experiments on the stainlesssteel material of the ExoMars 2020 Rosalind Franklin rover wheels. We show how tribocorrosion induced by brines accelerates wear on the materials of the wheels. Our results do not compromise the nominal ExoMars mission but have implications for future long-term surface operations in support of future human exploration or extended robotic missions on Mars.
\end{abstract}

\section{Introduction}

Tribocorrosion is a surface damage phenomenon resulting from the synergistic action of mechanical wear and (electro) chemical reactions. It can imply corrosion accelerated by wear, or wear accelerated by chemical reactions [1]. It was discovered in 1875 by Thomas Edison, who observed a variation in the coefficient of friction between metal and chalk moistened with electrolyte solutions [2], and today it is an important engineering topic, defined by ISO [3] and ASTM [4], and a cause for concern to any engineer employing passive metal components in corrosive environments [5]. If adequately controlled, tribocorrosion can be beneficial, such as in machinery lubricants where it is used as a means of avoiding seizure by promoting wear in a sacrificial mode [6]. Sacrificial mode is a concept in lubrication technology that is used to avoid seizure of mechanical components. Wear is promoted to reduce friction. This can be achieved by incorporating sulphur or chlorine via chemical additives in oil. Under conditions of wear, chlorine or sulphur reacts with nascent metal exposed by wear to produce iron chloride, which is weaker than the original steel.

The surface of Mars is rich in corrosive chemical species. Martian regolith contains abundant chloride [7] which forms various chlorides and perchlorate salts with high solubilities and low eutectic temperatures $[8,9]$. Detection of $0.4-0.6 \%$ perchlorate by mass in Martian high latitudes and further revelation of soluble chemistry of Martian soil at the Phoenix Lander site [10] were encouraging results prompting researchers to focus on perchlorate-based brine research. Other remaining anions and cations, as detected by the Wet Chemistry Laboratory on the Phoenix Mars Lander, were chloride, bicarbonate, and sulphate and $\mathrm{Mg}^{2+}, \mathrm{Na}^{+}, \mathrm{K}^{+}$, and $\mathrm{Ca}^{2+}$, respectively [10]. Subsequently, the reanalysis of the Viking results also suggested the plausible presence of perchlorate and organics at midlatitudes on Mars [11], as well as theoretical modelling at the landing site of InSight 
[12]. Evidence for sodium perchlorate $\left(\mathrm{NaClO}_{4}\right)$, magnesium perchlorate $\left(\mathrm{Mg}\left(\mathrm{ClO}_{4}\right)_{2}\right)$, and calcium perchlorate $\left(\mathrm{Ca}\left(\mathrm{ClO}_{4}\right)_{2}\right)$ has also been provided (with specific phases of the perchlorates not being determined yet) at equatorial latitudes by the Sample Analysis at Mars instrument on the Mars Science Laboratory (MSL) [13]. Another study [14] provides evidence of Martian perchlorate, chlorate, and nitrate in the Martian meteorite EETA79001 with sufficiently high concentrations. These results indicate the possibility that perchlorates might be abundantly present within Martian regolith at all latitudes. A variety of pathways have been proposed for the perchlorate synthesis on Mars. These pathways may involve photochemical reactions [15], electrostatic discharge [16], and oxidation-reduction reactions [17]. Perchlorates and chloride salts in the Martian regolith are extensively investigated because they can absorb water from the atmosphere forming hydrates [18], by absorption, and then liquid brines, through deliquescence $[19,20]$. In addition to perchlorates, chlorides such as $\mathrm{FeCl}_{3}, \mathrm{CaCl}_{2}$, and $\mathrm{MgCl}_{2}$ can also act as strong freezing point depressants. $\mathrm{FeCl}_{3}$ and $\mathrm{CaCl}_{2}$ are the strongest freezing point depressants with eutectic temperatures as low as approximately $218 \mathrm{~K}$, followed by $\mathrm{MgCl}_{2}, \mathrm{NaCl}$, and $\mathrm{KCl}$ at about $238 \mathrm{~K}, 252 \mathrm{~K}$, and $262 \mathrm{~K}$, respectively [9].

Perchlorates $\left(\mathrm{ClO}_{4}^{-}\right)$have been found planet-wide on Mars [10]. Studies show that the perchlorate salts which contain $\mathrm{ClO}_{4}{ }^{-}$anion can hold the water in brine state even when the temperature reaches $203 \mathrm{~K}$. Other chloride $\left(\mathrm{Cl}^{-}\right)$ salts have been detected such as magnesium chloride $\left(\mathrm{MgCl}_{2}\right)$ and calcium chloride $\left(\mathrm{CaCl}_{2}\right)$ [21], along with sulphate salts such as iron sulphate [22], which has deliquescent properties. Of course, the eutectic temperature of perchlorate is affected by cations, and not all chlorates have equally low eutectic temperatures.

A recent work [23] has derived the current chemical weathering rates on Mars, based on the oxidation of iron in stony meteorites investigated by the Mars Exploration Rover Opportunity at Meridiani Planum. The authors concluded that the chemical weathering rates derived are $\sim 1$ to 4 orders of magnitude slower than that of similar meteorites found in Antarctica where the slowest rates are observed on Earth, suggesting that aridity of Mars is even more significant than expected during the last $50 \mathrm{Myr}$. The authors extrapolated their results to the impact of weathering in the wheels of the NASA Curiosity rover, pointing out that Martín-Torres et al. [19] "worry that the corrosive effects of chlorine brine might pose a challenge to the rover. The extremely slow weathering of meteorites, which contain metallic iron as a phase very sensitive towards chemical alteration, suggests that this is not a threat over the lifetime of a spacecraft, however. The Opportunity rover is testament to that, showing no signs of chemical weathering or corrosion after more than 12 years of operating on Mars (April 2016).”

The argument used by Schroeder et al. (2016) to justify the absence of corrosion on mechanical parts on Mars actually supports the hypothesis that environmental conditions have an impact on the fate of the rover wheels. The wheels of Opportunity and Curiosity were similar in terms of composition and effective ground pressure supported (see
Materials and Methods). The fact that Opportunity showed no signs of chemical weathering or corrosion after more than 14 Earth years of operation on Mars (from 2004 until the middle of 2018), while Curiosity rover faced extreme corrosion and related punctures and tears just months after landing on Mars, maybe an indication of the impact of the local environment on wheels weathering. Actually, the details of this wear and tear on the wheels of Curiosity rover are missing from Schröder et al. [23].

Corrosion of the surface of a metal is the degradation that results from its chemical interaction with the environment. On Mars, any metal facing the sky, as the observable side of a meteorite, would only be exposed to the air, and thus only ambient oxygen would produce this damage. This is the case analysed by Schroeder et al. (2016), which considers only the chemical weathering rates of metals exposed to the Martian atmosphere. However, in the case of metals in contact with the regolith, as it is the case of the metals used in the wheels of the rovers operating on Mars, these materials may be eventually directly exposed to $\mathrm{Cl}$ and potential brines, which are formed naturally under Martian conditions at the interface of the regolith and the atmosphere [18-20]. These two processes are very different, as in the case of the wheels, in addition to the exposure to a liquid phase, there is the additional damage of mechanical wearing. It is known that metal can be protected from corrosion by covering it with a coating, such as an anodised treatment; however, as soon as this protective layer is scratched or worn out, the inner material is directly exposed to corrosion. Curiosity's wheel is made from a single piece of machined aluminium alloy AA7075-T7351. The main rim is $1.9 \mathrm{~cm}$ thick (0.75 inches) [23]. Martín-Torres et al. [19] hypothesised that the daily contact of the wheels with the corrosive perchlorate solutions during every night may have weakened the scratched surface of the anodised aluminium, making it more susceptible to damage against sharp rocks. Although the large cracks observed in the wheels of Curiosity are likely caused by mechanical damage, an image taken by the ChemCam Remote Microscopic Imager on Sol 502 in the vertical wall of the T-print of the wheels, showed a pattern of distributed submillimetre sized blisters that cannot be attributed to rock scratching and resembled aluminium alloy pitting corrosion [24]. Unfortunately, the Spirit and Opportunity rovers did not have an equivalent camera to analyse the wheels with submillimetre precision, so we cannot state whether this damage existed or not.

Previous preliminary experiments, designed to look at the interaction between aerospace aluminium alloy (AA7075-T73) and the gases present in the Mars atmosphere, at $20^{\circ} \mathrm{C}$ and a pressure of $700 \mathrm{~Pa}$ with only $0.13 \%$ of oxygen, showed that there is an interaction between the small amount of oxygen present in the Mars gas and the alloy, when there is a scratch that removes the protective aluminium oxide film [25]. The anodising process that is applied to aluminium alloy increases the thickness of the natural oxide layer on the aluminium wheels, but the abrasion can wear out the external protecting layer and expose the bare aluminium metal to corrosion. The purpose of this work is to evaluate the role of direct contact with 
liquid brines and the additional damage caused by mechanical friction.

Here, we present laboratory studies that show the impact of tribocorrosion (the combination of mechanical and corrosion wearing) on materials in contact with naturally formed brines under current environmental conditions on Mars. Although tribocorrosion is a well-known phenomenon since nearly 150 years ago, there is a lack of analysis of its impact on materials for landed spacecraft and structures that will support surface operations on Mars. Mechanical parts, like the wheels of the rovers operating on Mars, in contact with corrosive brines on the surface, could be affected by the combination of chemical corrosion and mechanical loading. Nevertheless, to our knowledge, no single research on tribocorrosion research on Mars has ever been published, even though corrosive materials have been found on the surface of Mars.

The European Space Agency ExoMars 2022 Rosalind Franklin rover will have a nominal lifetime of 218 sols (around 7 Earth months). Its mass is $310 \mathrm{~kg}$, with an instrument payload of $26 \mathrm{~kg}$ (excluding payload servicing equipment such as the drill and sample processing mechanisms). The rover's kinematic configuration is based on a six-wheel, triple-bogie concept with locomotion formula 6 . $6 \cdot 6+6$, denoting six supporting wheels, six driven wheels, and six steered wheels, plus six articulated (deployment) knee drives. This system enables the rover to passively adapt to rough terrains, providing inherent platform stability without the need for a central differential [26]. The wheels are made of Sandvik stainless spring steel 11R51 (https:// www.materials.sandvik/en/materials-center/materialdatasheets/strip-steel/sandvik-11r51/).

Here, we have performed laboratory studies on how the material (stainless spring steel) used in ExoMars 2022 Rosalind Franklin rover wheels is affected first by corrosion and then by tribocorrosion under environmental conditions on Mars. We suggest that similar studies should be conducted on other materials used for wheels and structures in contact with the Martian regolith.

\section{Materials and Methods}

2.1. Brine Corrosion under Martian Conditions. For the study of corrosion, we have tested samples of the Sandvik 11R51 stainless steel, used in the ExoMars 2022 Rosalind Franklin rover wheels, and two other control materials: stainless steel SS4301 and regular steel S235. Sandvik 11R51 is austenitic (US and Euro standards: AISI 301, EN 1.4310) stainless steel with excellent spring properties with higher corrosion resistance (due to the addition of molybdenum), mechanical strength, tensile strength and tempering effect, and fatigue and relaxation properties. Every material was exposed to two sets of salt environments inside the SpaceQ chamber at Martian conditions [27] (260 K and $6 \mathrm{mbar}$ ) and three control tests with salt (see Table 1) under ambient laboratory conditions (293 K and 1010 mbar). To simulate the Martian conditions, the chamber was first vacuumed and filled with pure $\mathrm{CO}_{2}$ gas till it reached 6 mbar. Then, water was injected to create water vapour in the atmosphere till $\mathrm{RH}$ reached $40 \%$, then the liquid nitrogen $\left(\mathrm{LN}_{2}\right)$ was allowed to flow through the cooling plate which reached a temperature of $260 \mathrm{~K}$, and then temperature was allowed to slowly increase to ambient lab conditions due to the thermal equilibrium.

Cases \#1 and \#2 were exposed for 5 hours to the Martian environment within the SpaceQ chamber, and to the simulated Martian water cycle described in Materials and Methods. The set of control samples \#1, \#2, and \#3 were left on the bench at laboratory conditions during the same time, and the control sample \#1 was immersed in a brine of $\mathrm{NaClO}_{4}(1.5 \mathrm{~g}$ salt $+1 \mathrm{~g}$ water) to observe the reactiveness of the material within the liquid already formed. After the experiments, the samples were packed in an airtight bag and studied using a scanning electron microscope (SEM) along with elemental detection via electron dispersive X-ray spectroscopy (EDS) to determine the effects of corrosion. The samples were only temporarily stored for transport in the airtight bag, and the clean metal was exposed during SEM.

The overview of the optical inspection by digital microscopy is shown in Table 2. We found no corrosion on either of the stainless-steel samples (11R51 or SS4301). On the contrary, the regular steel sample (Reg S235) presented visible signs of corrosion, both in Case \#1 (simulating Mars environment and immersed in the brine that is formed spontaneously by absorption of the moisture in the air) and in Case \#2 (simulating Mars environment and immersed in soil + salt), whereas the same immersion under ambient atmosphere produced less corrosion (Control \#2). This was qualitatively determined based on optical inspection with microscope. Examples are shown in Table 2. It is worth pointing out that these brines are formed spontaneously and are stable transiently at nighttime Martian surface conditions, depending on the season and local environmental conditions [19].

In order to identify spectrally the corrosion in S235 under Case \#1, we performed the analysis with the SEM-EDS as seen in Figures 1(a)-1(c). The digital microscope image in (a) shows clear visible signs of corrosion. A region that included corroded and noncorroded steel was selected for high magnification studies (green box). In (b), four regions along a vertical line were selected for EDS analysis. The EDS spectra in (c) show that regions related to spectra 3 and 4 are enriched in carbon ( $\mathrm{C}$ at $0.27 \mathrm{keV})$, oxygen $(\mathrm{O}$ at $0.52 \mathrm{keV})$, and sodium $(\mathrm{Na}$ at $1.04 \mathrm{keV})$ compared to the reference regions in spectra 1 and 2. These results are evidence of oxidation of the regular steel by the sodium perchlorate brine. Interestingly, carbon and oxygen, from the Martian atmosphere and the water in the brine and air, have also been fixed with different efficiencies from spectrum 1 to spectrum 4 , depending on the redox state of the material after the corrosion.

Actually, it is worth remarking that upon exposure to two different environments (Earth and Mars environments), the regular steel was more severely corroded under Martian conditions (Cases \#1 and \#2) than under ambient conditions (see for comparison Case \#2 vs. Control\# 2 in Table 2), so the corrosion of regular steel S235 is amplified under Martian conditions relatively to those on Earth. The brines were effectively formed under Martian conditions because of the high relative humidity conditions $(40 \% \mathrm{RH})$, whereas at ambient conditions in 
TABLE 1: Environmental conditions of the experiments performed with 11R51, SS4301, and S235.

\begin{tabular}{|c|c|c|}
\hline Case & Conditions & Salt environments \\
\hline$\# 1$ & $\begin{array}{l}\text { SpaceQ Martian conditions (pressure }=6 \text { mbar; } \\
\text { temperature }=260 \mathrm{~K} \text { ) }\end{array}$ & $1.5 \mathrm{~g} \mathrm{NaClO}_{4}$ (+water spontaneously absorbed from the atmosphere) \\
\hline$\# 2$ & $\begin{array}{l}\text { SpaceQ Martian conditions (pressure }=6 \text { mbar; } \\
\text { temperature }=260 \mathrm{~K} \text { ) }\end{array}$ & $\begin{array}{c}1.5 \mathrm{~g} \text { MMS soil }+0.15 \mathrm{~g} \mathrm{NaClO}_{4} \text { salt (+water spontaneously absorbed } \\
\text { from the atmosphere) }\end{array}$ \\
\hline $\begin{array}{l}\text { Control } \\
\# 1\end{array}$ & Laboratory conditions & $\mathrm{NaClO}_{4}(1.5 \mathrm{~g}$ salt $+1 \mathrm{~g}$ water $)$ brine immersion \\
\hline $\begin{array}{l}\text { Control } \\
\# 2\end{array}$ & Laboratory conditions & $1.5 \mathrm{~g}$ MMS soil $+0.15 \mathrm{~g} \mathrm{NaClO}_{4}$ salt \\
\hline $\begin{array}{l}\text { Control } \\
\# 3\end{array}$ & Laboratory conditions & Indoors (exposed to the air at ambient lab conditions) \\
\hline
\end{tabular}

TABLe 2: Optical inspection of the experiments.

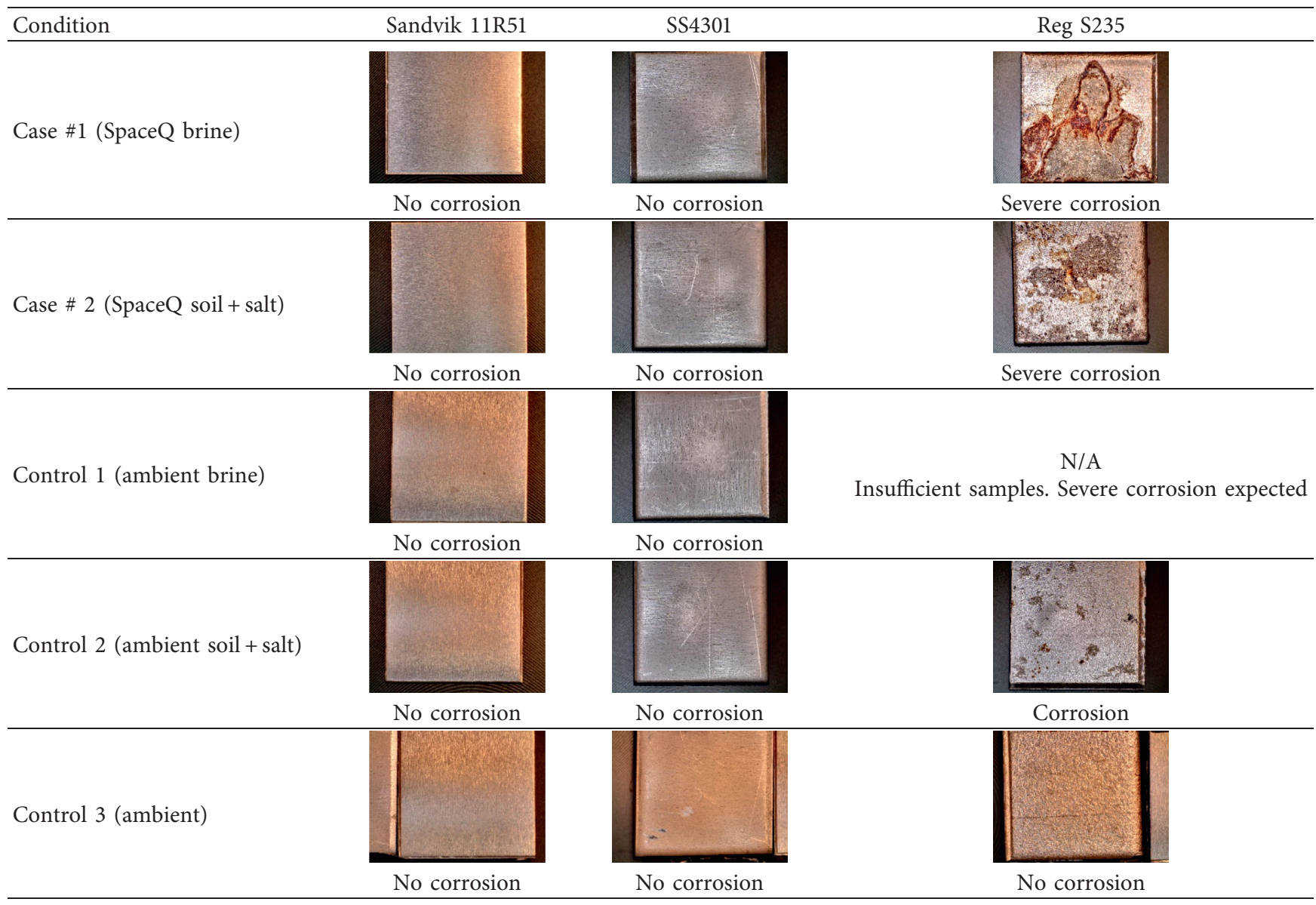

the laboratory the relative humidity was moderated $(10 \%$ $\mathrm{RH})$.

2.2. Tribocorrosion under Martian Conditions. As shown in Table 2, the material used in the ExoMars wheels (stainless spring steel Sandvik 11R51) showed no corrosion under static corrosion experiments, neither on Earth nor under Martian conditions. We have conducted a tribological experiment to evaluate if it is feasible to corrode (oxidise) stainless steel when subjected to wear while exposed to a liquid brine of the type that can be formed under Martian conditions. The experiment was conducted by rubbing for 90 minutes a $10 \mathrm{~mm}$ ceramic $\left(\mathrm{Si}_{3} \mathrm{~N}_{4}\right)$ ball against the material, while the plate was immersed in either brine or water (see Figure 2 for the setup). This is a standard procedure for testing tribocorrosion.

For the analysis we included the following (see Supplementary Materials): (i) measurements of friction during rubbing; (ii) wear volume by $3 \mathrm{D}$ optical profilometer; (iii) optical inspection with digital microscope; and (iv) scanning electron microscopy and electron dispersive X-ray spectroscopy (SEM-EDS) for detailed surface analysis including chemical (elemental) analysis.

Figure 3 shows the friction data and shows a clear difference between testing in water and brine. The friction coefficient is initially increasing to values above 1 , but for the wear test in brine the friction drops significantly after $30 \mathrm{~min}$ (1800s). The drop in friction could be explained by the 


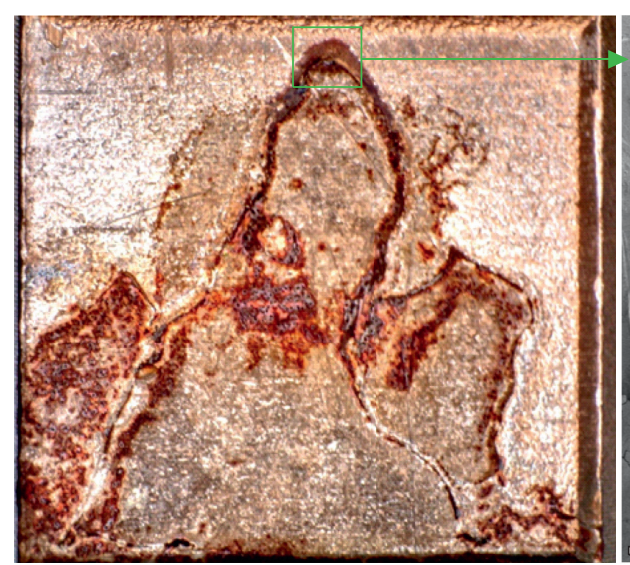

(a)

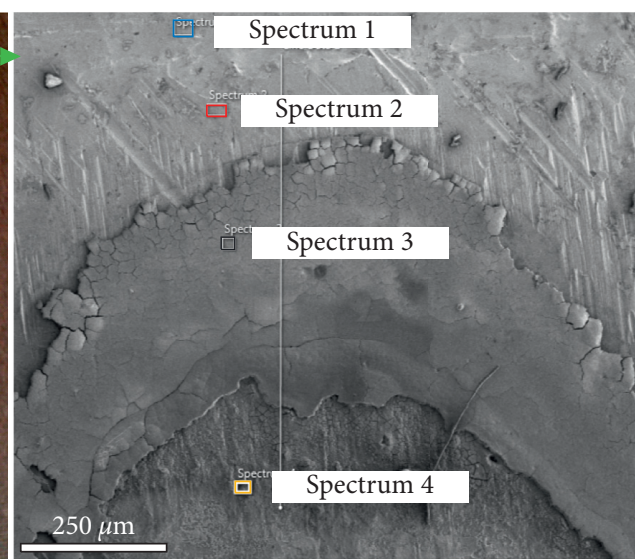

(b)

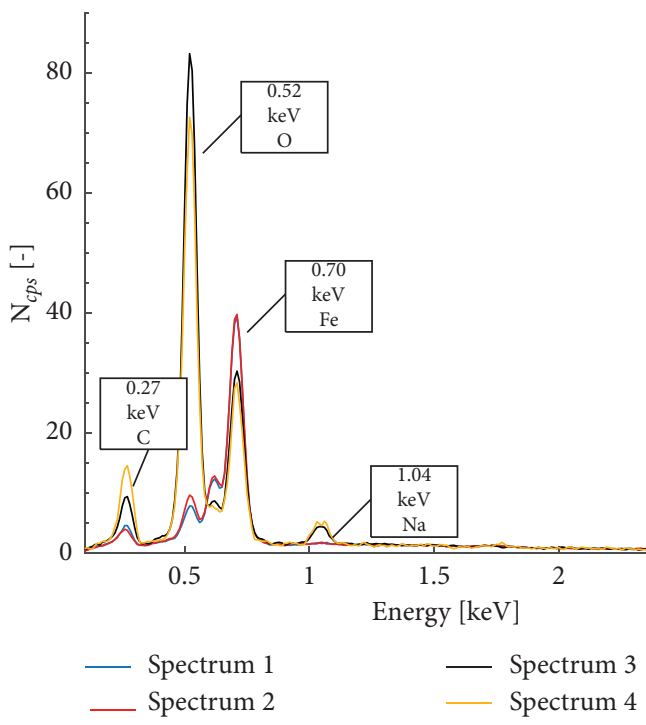

(c)

Figure 1: (a) Microscope image of $10 \times 10 \mathrm{~mm}$ regular steel sample. (b) High magnification SEM image showing location of EDS analysed regions. (c) Results of EDS analysis confirming corrosion by detection of $\mathrm{Na}$ and $\mathrm{O}$ in spectra 3 and 4.
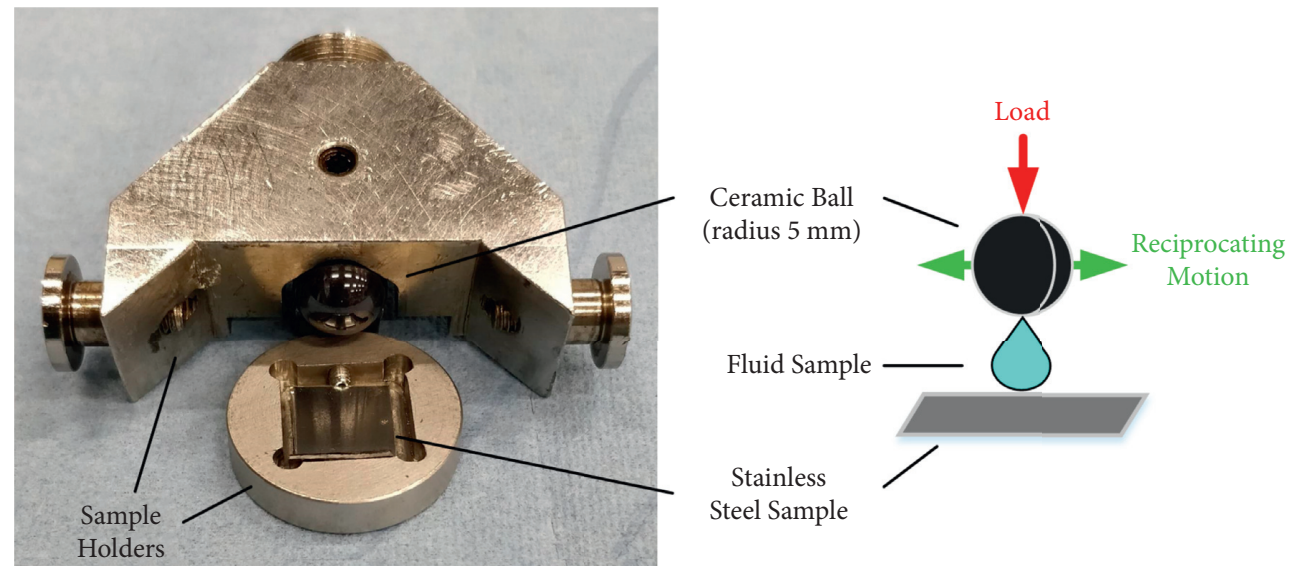

FIGURE 2: Setup of tribological experiment showing ceramic ball and stainless-steel plate in their respective sample holders.

chemical reactions that reduce the surface integrity and thereby lower friction. In tribology, this is known as sacrificial wear and is commonly employed in the antiseizure chemical additives known as extreme pressure agents (EP). They are used in extreme pressure gear lubrication, and they function by promoting wear so that friction is reduced. Chlorine containing EP agents has historically been used but is not recommended as it may cause corrosion [28]. 


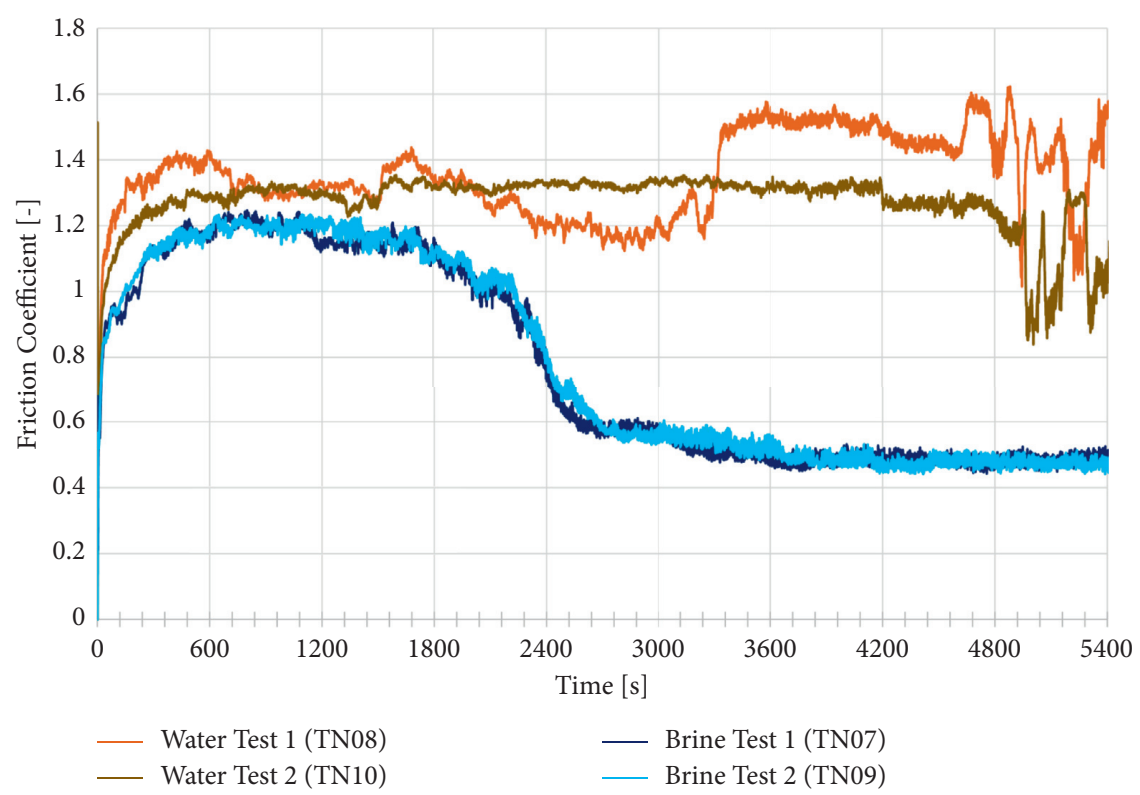

FIGURE 3: Friction data indicates transition to corrosive wear around time of $1800 \mathrm{~s}$ when immersed in brine.

TABLE 3: Wear data.

\begin{tabular}{lcccc}
\hline & Worn volume $\left(\mu \mathrm{m}^{3}\right)$ & Max depth $(\mu \mathrm{m})$ & Projected area $\left(\mathrm{mm}^{2}\right)$ & Worn volume per cycle $\left(\mu \mathrm{m}^{3}\right)$ \\
\hline TN07 brine & 80466771 & 41.2 & 3.16 & 1490 \\
TN08 water & 54217302 & 38.4 & 3.59 & 1004 \\
TN09 brine & 78590249 & 40.5 & 3.19 & 1455 \\
TN10 water & 26081611 & 19.6 & 3.53 & 483 \\
\hline
\end{tabular}

Table 3 shows that the worn volume is significantly increased $(>45 \%)$ when the test is performed in brine instead of water. TN10 has the lowest worn volume of all samples, indicating that brines have $>45 \%$ worn volume in these experiments.

The wear marks are shown in Figure 4 after washing the samples in two steps in heptane and ethanol in ultrasonic bath. The samples tested in water show a visual appearance that could be interpreted as corrosion, while the samples tested in brine are brighter in appearance except along the edges. The repeatability is good. Figure 5 shows an overview of the reference samples at low and high magnification and shows tests TN08 and TN07 (water and brine respectively). The edges of the wear marks were selected for further analysis. Figure 6 shows detection of $\mathrm{Cl}$ in worn area of TN07 (brine); Figure 7 shows evidence of surface oxidation but no detection of $\mathrm{Cl}$ in worn area of TN08 (water); and Figure 8 shows, as expected, no signals of $\mathrm{Cl}$, as test was run in deionised water. In this case, surface appears to be oxidised and is rich in Si (likely from ceramic Si3N4 ball).

The results shown in Figures $4-8$ can be summarised as follows: (i) a solution of $50 / 50 \mathrm{wt} \% \mathrm{NaClO}_{4}$ to $\mathrm{H}_{2} \mathrm{O}$ promotes wear when increasing the wear volume by over $45 \%$ in the tribological test; (ii) friction is significantly reduced by brine, compared with water; (iii) chlorine is detected in the wear track (<3 at\%); and (iv) friction and wear data, combined with chemical analysis, indicate that in comparison to water, the brine favours a sacrificial wear mechanism, meaning that friction is reduced at the expense of higher wear.

\section{Results and Discussion}

The main conclusion of these experiments is that brine accelerates wear by chemical reaction leading to a sacrificial wear mechanism. In the sacrificial wear mechanism, $\mathrm{Cl}$ reacts with the steel surface $(\mathrm{Fe})$ to reduce the toughness of the surface material. The consequence is that the resulting metal can wear more easily than the original did. This is a well-known concept in tribology-it is the basic principle relied on in antiseizure (also called extreme pressure) additives-where it is sometimes necessary to sacrifice material to reduce friction.

The experiments clearly demonstrate that wear under briny conditions result in a combination of a damaged passive layer and the presence of chlorides, which are the two factors usually associated with an increased risk of pitting corrosion. The duration of the presented experiment was about 5 hours, which is much shorter than the lifetime of the rovers on Mars. It can reasonably be assumed that the rovers' wheels, after a long exposition to the surface and Martian atmosphere, may get damaged. In that case, an oxide layer damaged by wear will not 


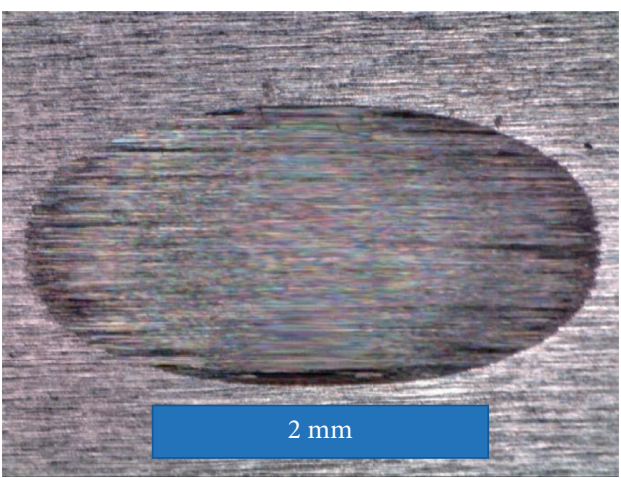

TN07 Brine

(a)

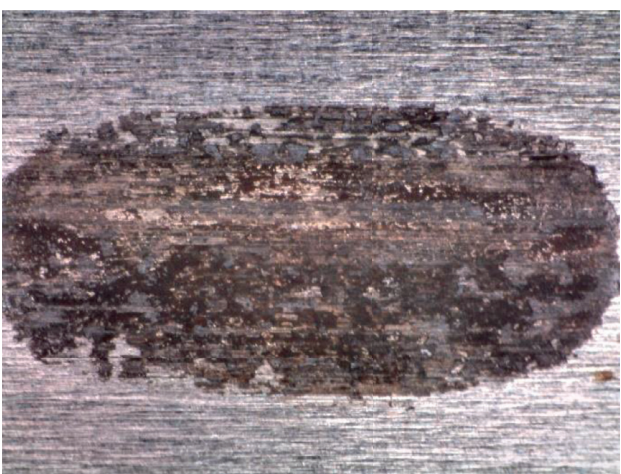

TN08 Water

(c)

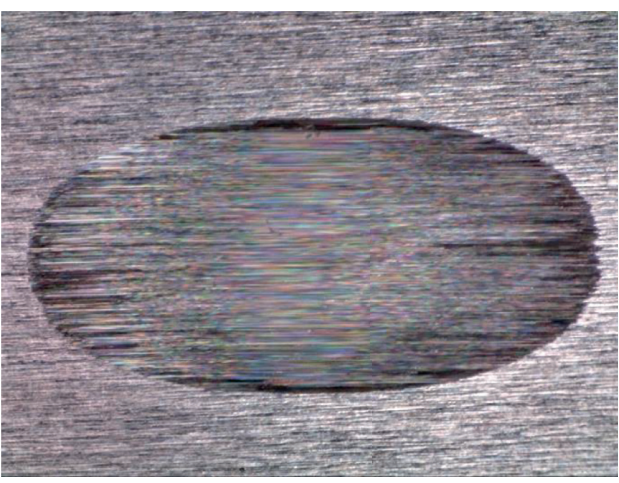

TN09 Brine

(b)

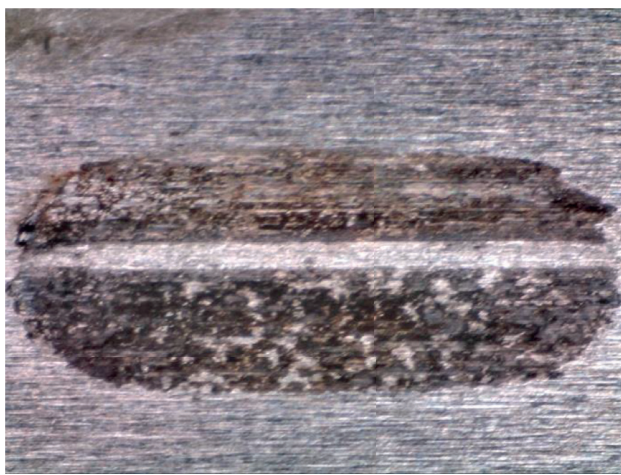

TN10 Water

(d)

Figure 4: Friction data (scale shown in (a)). (a) TN07 brine. (b) TN09 brine. (c) TN08 water. (d) TN10 water.

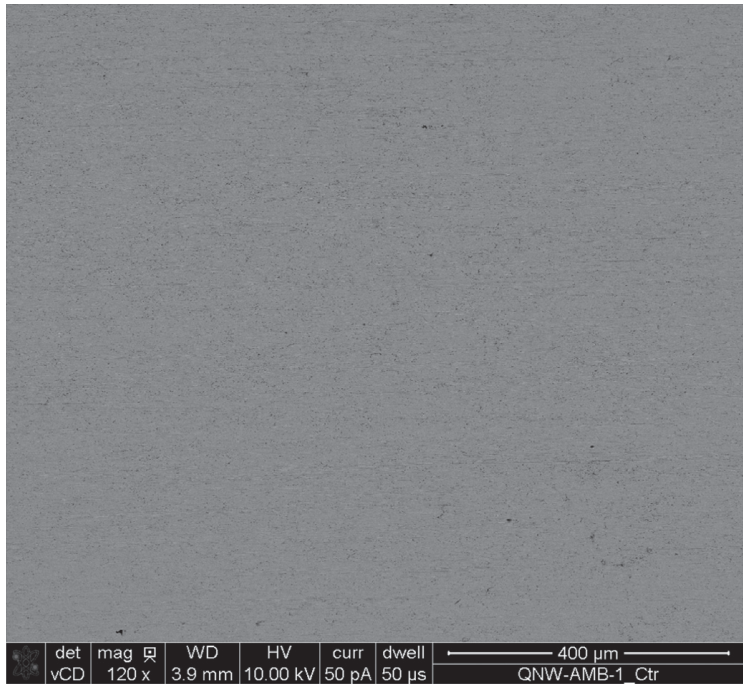

(a)

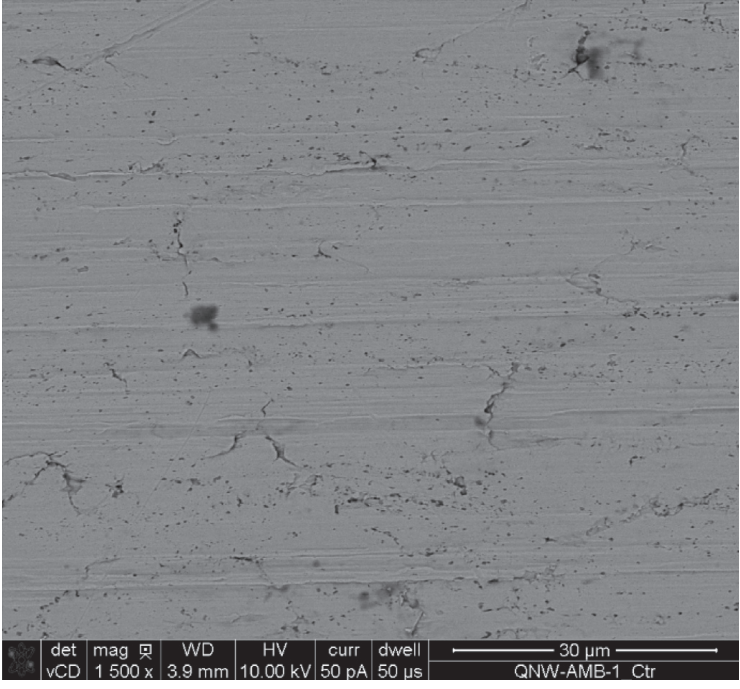

(b)

Figure 5: Continued. 


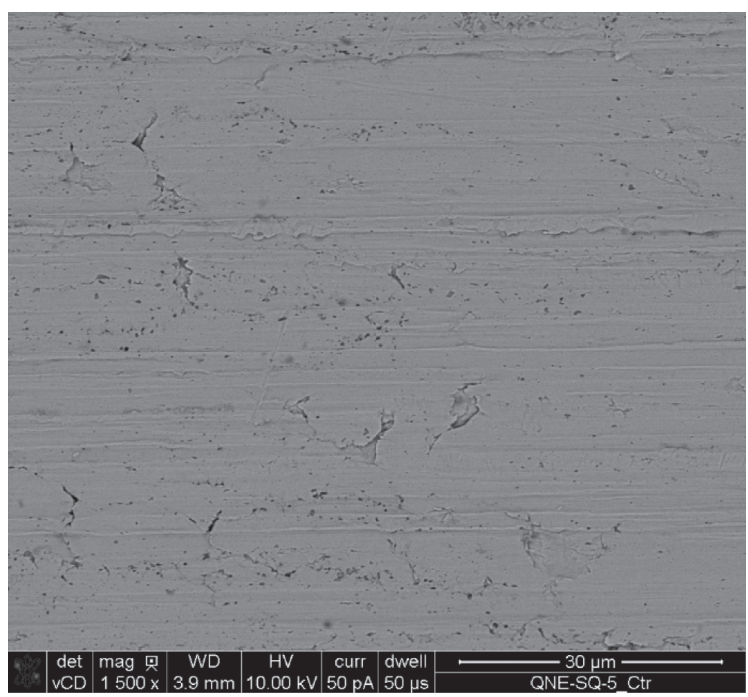

(c)

Figure 5: Reference samples (scale shown in the figures). (a) Reference sample 1 (ambient conditions) at low magnification. (b) Reference sample 1 (ambient) at high magnification. (c) Reference sample 2 (SpaceQ brine) at high magnification.

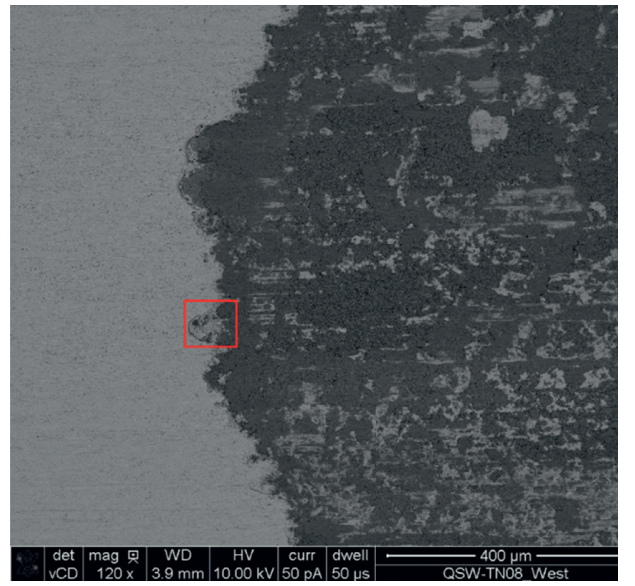

(a)

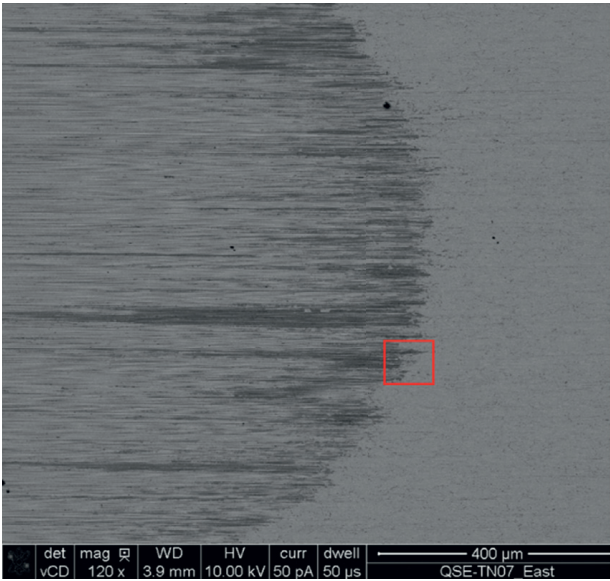

(b)

Figure 6: SEM overview of experiments: (a) TN08 (water). (b) TN07 (brine).

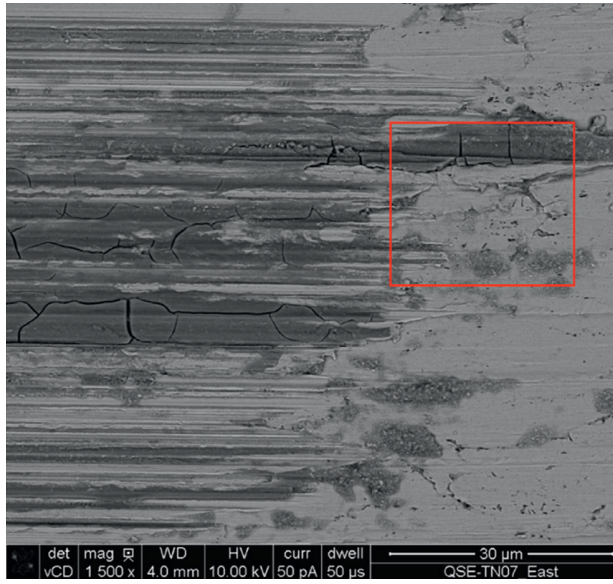

TN07 Brine, Edge of Wear Mark

(a)

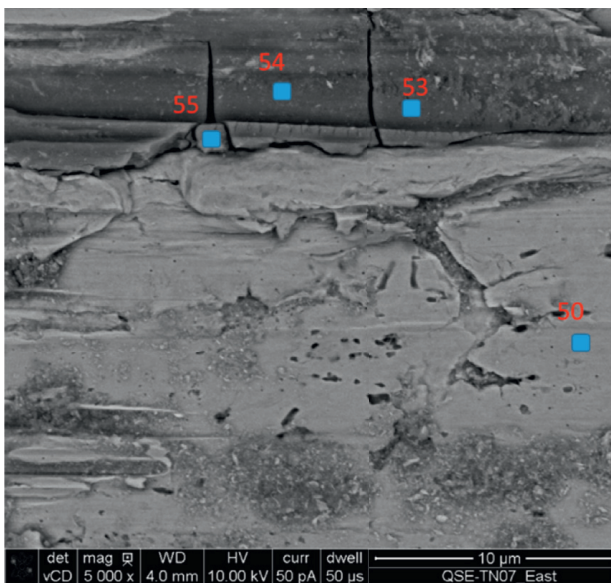

TN07 Brine High Magnification

(b)

FIgURE 7: Continued. 


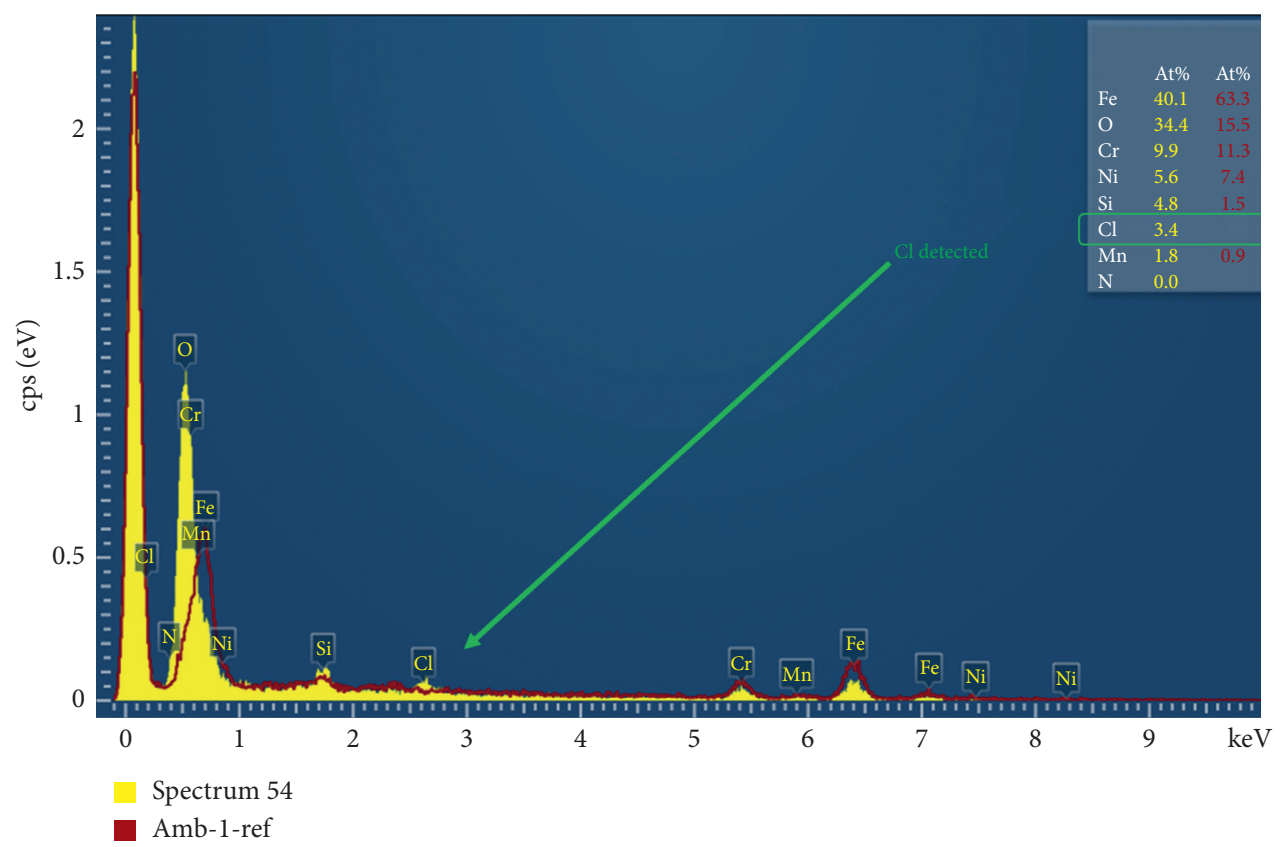

(c)

Figure 7: Detection of $\mathrm{Cl}$ in test with brine. (a) TN07 brine, edge of wear mark. (b) TN07 brine, high magnification.

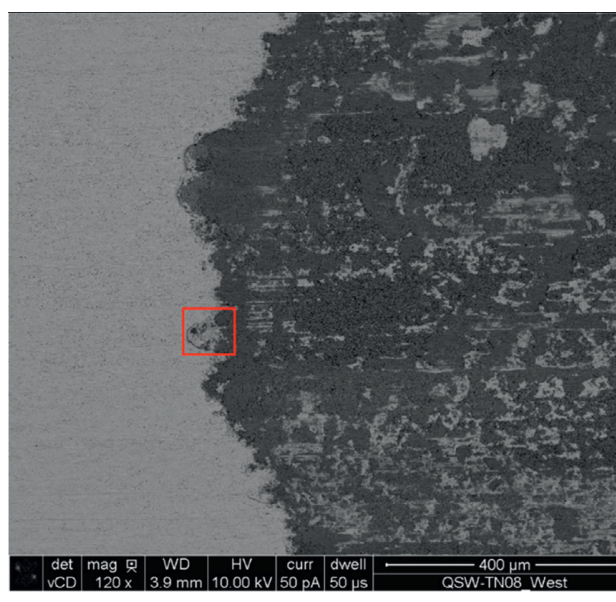

TN08 Water, Edge of Wear Mark

(a)

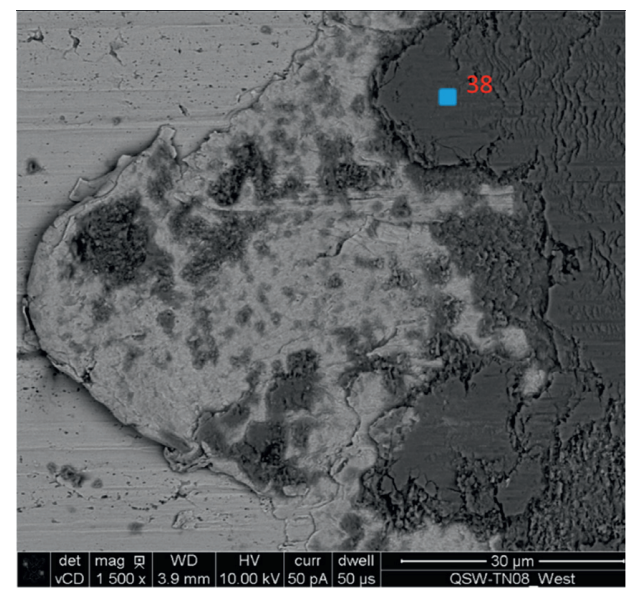

TN08 Water High Magnification

(b)

Figure 8: Continued. 


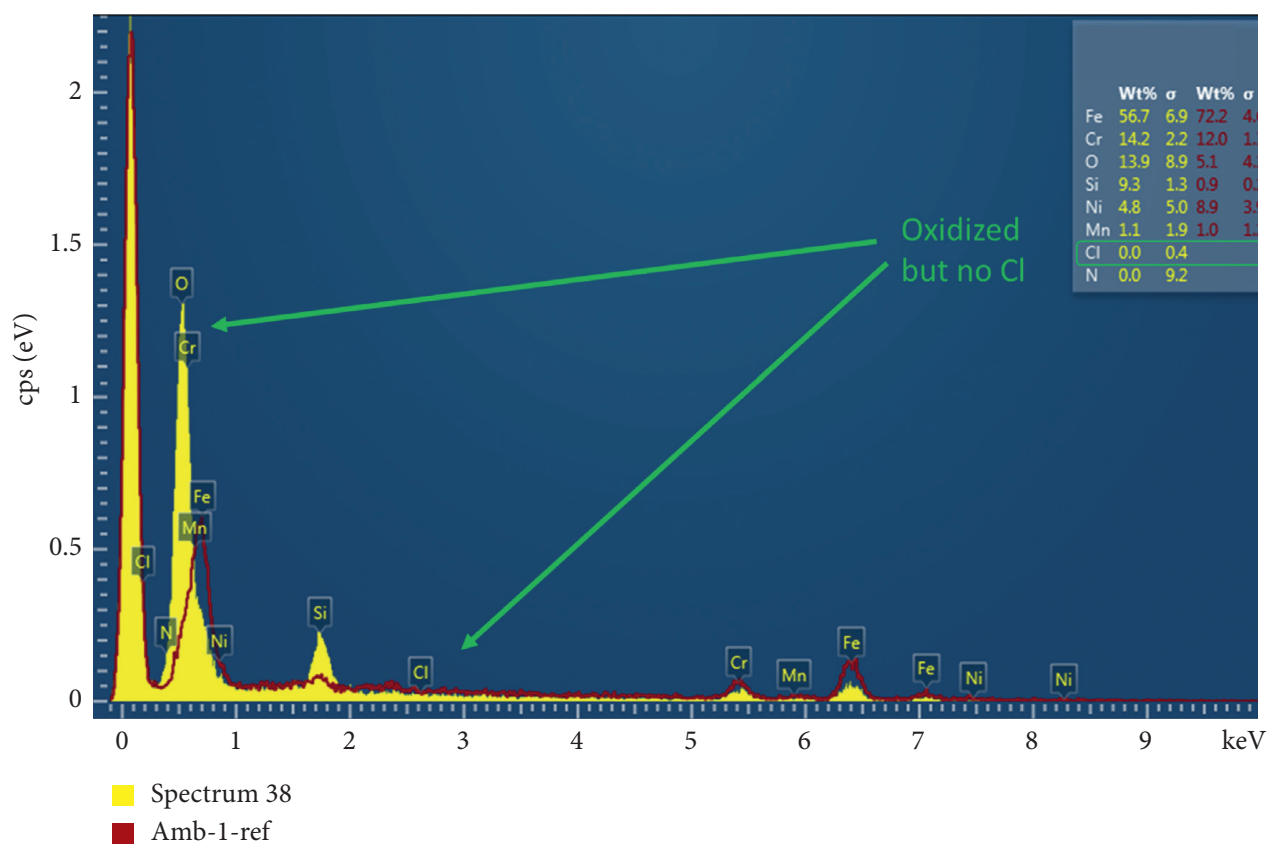

(c)

FIgUre 8: No Cl detected from water test. (a) TN08 water, edge of wear mark. (b) TN08 water, high magnification.

regenerate, due to the lack of available oxygen. Additionally, the experiments presented here are a conservative case (low corrosion case) of the real conditions of Mars, as other perchlorates, like $\mathrm{MgClO} 4$ and $\mathrm{CaClO} 4$, are the main perchlorates present on Mars [29].

From the surface analysis (SEM-EDS), it was clear that $\mathrm{Cl}$ was present in the steel surface material after the wear process in brine, and therefore the corrosion risk should be further investigated.

Although the materials used in Mars exploration may be resistant to chemical corrosion from brines in static conditions, mechanical wear only has to remove a few nanometres of oxide to accelerate the corrosion [30]. Tribocorrosion should not be overlooked in selecting materials or special protective treatments for landed spacecraft and structures that will support surface long-term operations for the human exploration of Mars, and in particular for the wheels of the Martian rovers that will operate for long term in the harsh conditions of Mars.

Further studies are needed to consider other important components of the Mars surface environment that can affect this interaction, such as the effect of oxidants, the effect of radiation on their oxidising properties, the possible catalytic effects of the minerals present in the Martian regolith, the diurnal thermal changes, and variation in ambient humidity, and in particular to develop more detailed studies including all the perchlorates existing on the surface of Mars to quantity the impact of tribocorrosion. Once on Mars, it would be useful to perform regular monitoring of the wheels with the robotic arm camera of the rovers. That would allow to observe and characterise the impact of tribocorrosion and also to infer the occurrence of brines on Mars.

\section{Data Availability}

All the data are available in the main text or the supplementary materials.

\section{Disclosure}

This manuscript has been uploaded to the open server of Research Square: https://www.researchsquare.com/article/ rs-36280/v1.

\section{Conflicts of Interest}

The authors declare that they have no known competing financial interests or personal relationships that could have appeared to influence the work reported in this paper.

\section{Authors' Contributions}

JMT was responsible for conceptualisation, supervision, investigation, writing the original draft, funding acquisition, and resources. MPZ contributed to conceptualisation, methodology, supervision, investigation, writing the original draft, and funding acquisition. EN carried out the tribocorrosion and corrosion experiments and reviewed and edited the manuscript. AVR conducted the corrosion experiments; provided experimental support to the tribocorrosion experiments; and reviewed and edited the manuscript. $\mathrm{AB}$ reviewed and edited the manuscript. 


\section{Acknowledgments}

The authors thank the ExoMars Project Team, European Space Agency (ESA), for reviewing the manuscript. The SpaceQ chamber has been developed in collaboration with Kurt J. Lesker Company and was funded by the Kempe Foundation. MPZ's contribution has been partially supported by the Spanish State Research Agency (AEI), Project No. MDM-2017-0737, Unidad de Excelencia "María de Maeztu"-Centro de Astrobiología (CSIC-INTA).

\section{Supplementary Materials}

The Supplementary Materials contain a detailed explanation of the steps followed in the brine corrosion and tribocorrosion tests and how the water and temperature cycle in the Martian near-surface have been performed. As complementary information, we give an estimate of the effective ground pressure of the Curiosity, Spirit, and Opportunity rovers. . (Supplementary Materials)

\section{References}

[1] S. W. Watson, F. J. Friedersdorf, B. W. Madsen, and S. D. Cramer, "Methods of measuring wear-corrosion synergism," Wear, vol. 181-183, pp. 476-484, 1995.

[2] T. Edison, Improvement in Telegraph Apparatus, 1875.

[3] International Organization for Standardization, International Organization for, S. Corrosion of Metals and Alloys - Vocabulary (ISO 8044:2020), International Organization for Standardization, Geneva, Switzerland, 2020.

[4] American Society for, T. \& Materials, 2017.

[5] D. Landolt and S. Mischler, Tribocorrosion of Passive Metals and Coatings, Woodhead Publishing Limited, Sawaton, UK, 2011.

[6] G. W. Rowe, "The chemistry of tribology, friction, lubrication and wear," Royal Institute of Chemistry Reviews, vol. 1, no. 2, pp. 135-204, 1968.

[7] A. Bhardwaj, L. Sam, F. J. Martín-Torres, and M. P. Zorzano, "Are slope streaks indicative of global-scale Aqueous processes on contemporary Mars?” Reviews of Geophysics, vol. 57, no. 1, pp. 48-77, 2019.

[8] A. Bhardwaj, L. Sam, F. J. Martín-Torres, M.-P. Zorzano, and R. M. Fonseca, "Martian slope streaks as plausible indicators of transient water activity," Scientific Reports, vol. 7, no. 1, p. $7074,2017$.

[9] B. Clark and D. van Hart, "The salts of Mars," Icarus, vol. 45, no. 2, pp. 370-378, 1981.

[10] M. H. Hecht, S. P. Kounaves, R. C. Quinn et al., "Detection of perchlorate and the soluble chemistry of martian soil at the Phoenix lander site," Science, vol. 325, no. 5936, pp. 64-67, 2009.

[11] R. Navarro-González, E. Vargas, J. de la Rosa, A. C. Raga, and C. P. McKay, "Reanalysis of the Viking results suggests perchlorate and organics at midlatitudes on Mars," Journal of Geophysical Research, vol. 115, no. E12, 2010.

[12] P. Bernadett and Á. Kereszturi, "Annual and daily ideal periods for deliquescence at the landing site of InSight based on GCM model calculations," Icarus, vol. 340, Article ID 113639, 2020.

[13] D. P. Glavin, C. Freissinet, K. E. Miller et al., "Evidence for perchlorates and the origin of chlorinated hydrocarbons detected by SAM at the Rocknest aeolian deposit in Gale
Crater," Journal of Geophysical Research: Planets, vol. 118, no. 10, pp. 1955-1973, 2013.

[14] S. P. Kounaves, B. L. Carrier, G. D. O’Neil, S. T. Stroble, and M. W. Claire, "Evidence of martian perchlorate, chlorate, and nitrate in Mars meteorite EETA79001: implications for oxidants and organics," Icarus, vol. 229, pp. 206-213, 2014.

[15] D. C. Catling, M. W. Claire, K. J. Zahnle et al., "Atmospheric origins of perchlorate on Mars and in the atacama," Journal of Geophysical Research, vol. 115, 2010.

[16] K. Tennakone, "Contact electrification of regolith particles and chloride electrolysis: synthesis of perchlorates on Mars," Astrobiology, vol. 16, no. 10, pp. 811-816, 2016.

[17] B. L. Carrier and S. P. Kounaves, "The origins of perchlorate in the Martian soil," Geophysical Research Letters, vol. 42, no. 10, pp. 3739-3745, 2015.

[18] L. Ojha, M. B. Wilhelm, S. L. Murchie et al., "Spectral evidence for hydrated salts in recurring slope lineae on Mars," Nature Geoscience, vol. 8, no. 11, pp. 829-832, 2015.

[19] F. J. Martín-Torres, M.-P. Zorzano, P. Valentín-Serrano et al., "Transient liquid water and water activity at Gale crater on Mars," Nature Geoscience, vol. 8, no. 5, pp. 357-361, 2015.

[20] E. G. Rivera-Valentín, V. F. Chevrier, A. Soto, and G. Martínez, "Distribution and habitability of (meta)stable brines on present-day Mars," Nature Astronomy, vol. 4, no. 8, pp. 756-761, 2020.

[21] M. M. Osterloo, F. S. Anderson, V. E. Hamilton, and B. M. Hynek, "Geologic context of proposed chloride-bearing materials on Mars," Journal of Geophysical Research, vol. 115, no. E10, 2010.

[22] V. F. Chevrier and T. S. Altheide, "Low temperature aqueous ferric sulfate solutions on the surface of Mars," Geophysical Research Letters, vol. 35, no. 22, 2008.

[23] C. Schröder, P. A. Bland, M. P. Golombek, J. W. Ashley, N. H. Warner, and J. A. Grant, "Amazonian chemical weathering rate derived from stony meteorite finds at Meridiani Planum on Mars," Nature Communications, vol. 7, no. 1, p. 13459, 2016.

[24] C. Vargel, Corrosium of Aluminium, 2004.

[25] L. M. Calle, W. Li, M. R. Johansen, J. W. Buhrow, and C. I. Calle, Corrosion on Mars: An Investigation under Relevant Simulated Martian Environments, 2017.

[26] J. L. Vago, F. Westall, A. J. Coates et al., "Habitability on early Mars and the search for biosignatures with the ExoMars rover," Astrobiology, vol. 17, no. 6-7, pp. 471-510, 2017.

[27] A. Vakkada Ramachandran, M. I. Nazarious, T. Mathanlal, M.-P. Zorzano, and J. Martín-Torres, "Space environmental chamber for planetary studies," Sensors, vol. 20, no. 14, p. 3996, 2020.

[28] L. R. Rudnick, Lubricant Additives : Chemistry and Application, CRC Press, Florida, FL, USA, 2003.

[29] S. Civiš, A. Knížek, P. B. Rimmer et al., "Formation of methane and (Per)Chlorates on Mars," ACS Earth and Space Chemistry, vol. 3, no. 2, pp. 221-232, 2019.

[30] L. M. Calle, Corrosion on Mars: Effect of the Mars Environment on Spacecraft Materials, 2019. 